\title{
DeVeloping A Self-PACEd Course Module IN INFORMATION-FINDING AND LITERACY SKILLS FOR COURSE- BASED MASTERS' STUDENTS
}

\author{
Evan Sterling, B.Sc.(Eng), MIS and Jolene Hurtubise, B.Sc., MI \\ University of Ottawa, Ottawa, Ontario \\ Evan.sterling@uottawa.ca,jhurtubi@uottawa.ca
}

\begin{abstract}
Academic librarians in Canada often teach information research skills and information literacy to students, including engineering students, via class presentations. These skills include knowledge of the diverse technical information sources available, the use of specialised databases and free search tools, and assessing and properly citing information; they are important in graduate studies and in engineering practise. Course-based masters' students are a growing demographic in engineering, however their particular needs have not as often been targeted by librarians. In this project, we developed a graded asynchronous course module in these skills, for a new course in professional skills for M.Eng. students. It uses text, images, videos, short assignments and quizzes to follow the general research and writing process for a technical report, marking a significant increase in the contact time for these skills. To date the unit has been taught twice, to over 200 students, with overall feedback being positive. We plan to continue its development and make it openly available.
\end{abstract}

Keywords: Information literacy; Engineering libraries; Asynchronous learning; Online education;

Module-based learning

\section{INTRODUCTION}

This project was led by two librarians who work with engineering students at the University of Ottawa. Like at most Canadian universities, librarians guest-lecture in particular undergraduate and graduate science and engineering courses on topics such as the types of highquality technical engineering information, running effective database searches, and referencing sources properly. Usually, these presentations are 45-90 minutes long, provide only a brief introduction to each of these skills, and are tied to a particular assignment such as a design report or literature review paper. From the perspective of librarians this is not a particularly efficient or effective method of teaching these skills, since the limited length means that presentations are often overloaded with an overview of essential information, without sufficient depth to reinforce the concepts; there is considerable literature in librarianship on maximizing these "one-shot" presentations (such as [1]).

Demand for these presentations in engineering programs has remained despite these limitations, as well as after the rise of Google Scholar and other simple methods of searching literature, since instructors continue to notice skill deficiencies in this area, among bachelor's, master's and doctoral students. For Canadian university programs overall, a survey indicated that the proportion of librarians teaching to graduate students has remained roughly flat over the past 20 years [2].

There are also few mandatory core courses or seminars in the graduate engineering programs at our university, which means that typically librarians present in particular technical courses which have a research-based assignment. As a result, some students would participate in several of these overview presentations over the course of their degree, while others would not experience any.

The term "information literacy" or IL is commonly used by librarians but may be unfamiliar to other readers. It has been used to refer to various skills from the 1960s onwards, as outlined by [3], ranging from the more traditional "[locating and using] information needed for problem-solving and decision-making" to more recent definitions emphasizing the importance of thinking critically about sources and types of information. Often, IL instruction has emphasized the primacy of peer-reviewed literature and academic databases above all else; however, in engineering, other sources like reports and handbooks are considered equally valid and students need to learn how to find them and assess their quality. Recently, the most influential work has been a framework of six core concepts for learners to understand about information in a scholarly context, published by the Association of College and Research Libraries in 2015. These concepts are: Authority Is Constructed and Contextual; Information Creation as a Process; Information Has Value; Research as Inquiry; Scholarship as Conversation and Searching as Strategic 
Exploration [4]. Communicating these complex ideas is not an easy task, especially in the course of a single presentation, and the language used in the framework is not always relevant to our audience of engineering students. However, certain ideas are beneficial in this context - particularly the ideas that information creation is a process which varies by the type and source of information; that searching is an iterative, exploratory process that requires creativity; and that different pieces of information have various degrees of credibility and relevancy, which may or may not be suitable for a particular need.

The previous literature on information literacy in engineering students or STEM students has generally focused on undergraduate or thesis-based graduate students. With undergraduate students, there is a need to introduce them to the range of technical and trade information used in design projects, some of which is found outside of academic databases. In addition to searching, Canadian librarians have focused on teaching quality assessment or "critical appraisal" of documents, from any sources (e.g. [5]); and also, on basic standards of academic integrity and citing (e.g. [6]).

With thesis-based masters or doctoral students, there is an additional need to focus on advanced methods for obtaining access to particular resources (such as hard-tofind papers), refining a broad research question into a wellscoped search topic, as well as advanced use of databases. Librarians across Canada are actively involved in teaching these skills to engineering graduate students. One of the authors of this paper regularly presents in graduate seminars for students in civil and environmental engineering and will be involved in the teaching of a new research methods course for thesis students in civil engineering. At École Polytechnique, librarians have taught a partial-credit mandatory course for all thesis-based graduate students for over a decade [7]. In a study of American social sciences and humanities graduate students, [8] noted that many reported wanting assistance acquiring skills that their supervisors do not teach them as they are considered a basic part of the research process - such as note-taking, refining a research topic, and organizing the "mountain of information" that is available online. We notice similar trends among engineering students at our university, who often ask us for assistance with these skills that are outside of the 'core' librarian teaching of finding information on a given topic. Professors and supervisors either do not have time to help students with these skills, or students are reticent to ask for help for fear of how this would be perceived.

The information skills and literacy needs of students in course-based (non-thesis) masters programs are similar to but distinct from the above two populations. At uOttawa, these programs have grown significantly and now comprise the majority of graduate student enrolment. Overall graduate and master's enrolment has approximately doubled over the past 10 years (however M.Eng. enrolment is not specifically available publicly) [9]. They do not write theses, and rarely work on in-depth research projects during their program. However, they are required to write literature reviews in many courses, and their program works to prepare them for professional engineering work that often involves locating and using specific technical information. The CEAB's required graduate attribute no. 12, Lifelong Learning, is also very relevant for master's program graduates [10]. They often show little existing knowledge of these skills that might have been gained during their undergraduate degree. At our university, like some other Canadian engineering schools, a significant majority of course-based masters' students are international (for example, in the Electrical Engineering program, $77 \%$ of all master's students were international in the most recent academic year [9]). This results in additional variation in the pre-existing skills and knowledge of students in this area, since universities in other regions may not have access to the same level of scholarly information resources, and undergraduate engineering courses may not provide students with as many opportunities to develop information research skills. In particular, professors have commented on a lack of student understanding regarding the requirements for citing and plagiarism. In [11], the authors summarize previous literature and note that reasons for plagiarizing among international students, and all students, are complex, generally including unfamiliarity with Western concepts of academic citation, and a perception that plagiarism is widespread among fellow students. The stereotype that international students are "inherently plagiarizers" is unhelpful, but pedagogy must still adapt to avoid assuming pre-existing knowledge. In our experience, there is a wide variation in familiarity with academic integrity and information literacy among both international and domestic students. That being said, we do receive more frequent questions from international students about academic integrity and plagiarism; in particular, students asking for access to plagiarism self-checking tools such as TurnItIn, indicating that they are unsure whether they are in accordance with current academic expectations.

At the University of Ottawa, an opportunity presented itself through the development of a new course for coursebased masters students in Professional Skills. This course originated from a series of optional workshops in professional skills aimed at international graduate students, the Hojjat Salemi International Students Workshops. One of the authors of this paper presented on the topic of searching and source evaluation in that workshop series. The coordinator at the time was the Vice-Dean of Graduate Studies of the Faculty of Engineering, and after the workshop, in late 2019 he proposed an online module so students could learn these skills asynchronously. This idea evolved into a graded course module, as part of this new 
course in professional skills (which is currently mandatory for M.Eng. students in electrical engineering and is planned to be mandatory for such students in other departments as well). The program calendar states that the course should be completed in the first semester of enrolment. The rest of the course focuses on job searching, networking, delivering presentations, interviewing, writing reports and working in teams.

This opportunity addressed the need for more instructional time devoted to these skills, and more consistency in reaching the large audience of masters' students each year. Prior to the pandemic, the module was envisioned as a hybrid online/in-person experience. It would consist of an asynchronous online module, containing educational material with quizzes and assignments, and culminating in an in-person session to allow for a group activity. Due to the approach that was outlined, the sudden change to online teaching as a result of the pandemic did not result in any major changes to our plan, with only a small shift from a culminating in-person activity to a live online session.

\section{METHODS}

The development of this module consisted of three main design decisions; the platform on which it would be hosted, the content that would be contained within, and the format of the content.

The first step in our process was determining which platform would be used to host our module. We began by outlining the features that we required in a platform and then compared those with commonly used platforms and resources available institutionally. Quickly, we had narrowed our potential platforms to our institution's learning management system (D2L Brightspace), LibGuides (a webpage authoring, and content management system designed for university libraries), and Articulate 360 (an e-learning delivery platform). While each of these options had their advantages and limitations, we ultimately chose Brightspace. In addition to Brightspace being available through the university, we discovered that it had the capabilities that we required and had support services provided through the institution. While Articulate 360 was more suited than the other options to a stand-alone self-paced module, the fees and specialized expertise required to use it presented difficulties when considering a long-term perspective. When looking at the future use of the module, Brightspace was the most promising option as it is more universally known, making it easier to pass along to future colleagues or be adapted for other institutions or contexts. While Brightspace has served as a good platform for this educational material, we did face some difficulties. Although this is the learning management system (LMS) used and supported by our institution, librarians do not have access by default. In order to create this module, we had to request special course spaces and learn the intricacies of the platform. We were able to become proficient in this platform through a combination of consultations with our institution's teaching and learning support services and exploration of the various tools and features.

After having chosen our platform and become familiar with its capabilities, we decided what content would be delivered in this module, as well as what material would be covered in the online platform versus the live session. We wanted to ensure that the material within these two elements complemented each other, ultimately enhancing the students' learning experience, rather than introducing redundancy. In order to give a well-rounded experience to the students, we decided that our asynchronous online module would be where the students acquired the skills, while the live session would serve to reinforce their learning through participation in a student-driven topic selection and search exercise, as an example of these skills in action.

To make the online module more digestible, we separated the content into six short sub-modules. These sub-modules explained key definitions and terminology commonly seen in research and took the students sequentially through the steps involved in researching technical information. The first sub-module describes and provides examples of various source types (ex. articles, books, conference proceedings, patents, etc.), along with a short quiz, as well as an overview of the peer review process. The second sub-module outlines the steps to planning your research and creating a search strategy. This includes refining the topic, choosing search terms, and adding search operators. This section features both a short quiz, as well as the first written assignment, where students were required to develop a search for a highly specific topic chosen from a list we provided (such as safety testing methods for self-driving cars). In the following submodule, we dive into the various types of search tools available (including academic databases like Web of Science, Scopus and IEEE Xplore) and provide demonstrations of those most commonly used. The assignment featured in this section builds on the one from the previous section and asks students to run the search that they created and iteratively improve it in order to retrieve relevant articles. Once we have retrieved some results, we continue onto sub-module four where we discuss some key criteria that can be used to evaluate the quality and relevancy of what was retrieved. This section includes the module's final assignment, where (in groups) students are asked to evaluate the credibility and usefulness of provided scholarly and non-scholarly documents for a particular topic using multi-dimensional criteria. In submodule five we finish off the research process by explaining citing and referencing best practices so that students can effectively and appropriately use the sources they have found. It is in this section where the module's 
final quiz is presented. In our most recent set of improvements, we have added the sixth sub-module which discusses and provides resources pertaining to writing styles and formatting. During the live session, which occurs after the module has been completed, we provide a brief summary of the module and then work through a research example live using suggestions from the students.

While the content covered within the module includes information literacy and research skills common to most programs, we wanted it to address the specific needs of the students within this program. We did this in three main ways. To fit our majority international-student audience, we wanted to cover the basics of research within the Canadian academic context as well as what practices would be expected of them in academia and the professional workplace. Secondly, we incorporated elements specific to engineering throughout the entire module. Conceptually, we emphasized that research and searching is an iterative process, as in design, and used infographics to speak in an engineering visual language. We included information on standards and other source types highly utilized in engineering, demonstrations of commonly used databases such as Scopus and IEEE Xplore, explanations and resources for citing practices in both APA and IEEE, as well as resources to learn more about formatting their writing based off IEEE or ACM requirements. Lastly, we provided information and examples utilizing resources that they would continue to have access to after graduation. These included demonstrations of free search tools, such as Google Scholar, Advanced Google, and 1 findr, as well as examples of how to assess the quality of the information you would find in non-academic sources.

Just as important as deciding what content would be included, was deciding the format in which that content would be presented. We prioritized using several different formats, as opposed to just text, to help increase the students' interactivity and interest in the module. To achieve this, we used a wide range of formats, including text, infographics, interactive 'hotspot' images, image carousels, videos, quizzes and short assignments. The video format allowed us to provide in-depth explanations of Boolean syntax and demonstrations of each database, with videos being a maximum of 10 minutes each. In order to produce all of these, we used tools available within the LMS (text, quizzes, assignments), software accessible through the library (Screencast-O-Matic, VideoScribe) and external resources (Canva, H5P). Accessibility was a priority for us, and so for all elements that relied on visuals we provided captions and transcripts to make the information as inclusive as possible. One difficulty that we faced was ensuring that our material would be accessible to those students not currently studying in Canada. For example, our videos are uploaded to YouTube, as videos uploaded directly to Brightspace require more bandwidth and cause difficulties for those with poor internet connection, however YouTube is not accessible globally.
As a result, we placed our videos on YouTube, as well as on an additional page at the end of the module where they were uploaded directly to Brightspace, providing a backup option for students.

At the request of the course instructor, we created a shareable micro-credential for students who completed the module work (using the platform Badgr) which could be added to their LinkedIn profile. This is part of a broader desire within the Faculty of Engineering to use microcredentials to quantify and market transferable skills gained by students that may not be reflected in course titles on their transcripts.

Since the creation of a learning module was a new endeavour for us, we wanted to utilize the university's services and resources and incorporate feedback from several different perspectives. Prior to creating the module, we benefited from a series of consultations with an online pedagogy specialist from our teaching and learning support services (TLSS) at the university. It was here that we learned about the best practices in creating a hybrid learning module as well as the resources available to help us meet our goals. We also had several meetings with the professor who was running the professional skills course. Through these meetings, we received feedback on the relevancy of the information presented for their students. Prior to launching the module, it was important to us to test it with students in this program. The professor was able to set us up with two graduate level engineering students to beta test the module. The students went through the entire module, completing all quizzes and assignments and providing feedback in written form and during a meeting. These suggestions focused on the effectiveness of the chosen formats, the clarity of the information presented as well as pointing out any areas of the module that were not relevant to their needs or applicable elements that were not included. After the first semester that the module was in place, we used the students' completed assignments and quizzes to pinpoint areas that could be further improved. At this point we also had several of our librarian colleagues review the module. They were able to provide more feedback in the areas concerning the instructional methods used within the module. Improvements identified in both of these avenues were incorporated into the module before beginning its second semester.

\section{Results}

To date the module has been taught twice, in fall 2020 and winter 2021 semesters, to over 200 students. After our first semester a total of 144 out of 158 students successfully completed the module. From the results obtained on the quizzes, and the personalized feedback that we provided for the individual assignments, it was clear that the students were very engaged in the process and were putting effort into the module. We did notice common 
patterns in student work that indicated that they had not grasped some of the specific, complex aspects of search query construction and quality evaluation, which we then addressed during the live session. The final grades and feedback from the winter 2021 semester has followed a similar trend, with students being very engaged in the material and exercises resulting in 65 out of 68 students successfully completing the module.

After running the live session, we provided the students with a short survey. Based on the answers and feedback provided on the survey, the module has been overall very well received, with most respondents stating that the module and live session were either excellent or very good. Using a scale to rate the quality and contents of the module, the majority of survey responses indicated that they felt the topic was either extremely useful or very useful, and that there is potential interest in hearing more about this topic in future presentations. When the students were asked in an open text question which elements they had found to be the most useful, the demonstrations, examples, and clear step-bystep instructions on how to build your search strategy and use the various search tools was mentioned repeatedly. Additionally, they were asked which elements they disliked and whether they had any suggestions for improvement. While the majority of feedback received was positive, there were some suggestions to add more examples to help improve clarity, to add more practical exercises related to citations and to focus more on skills applicable in the workplace since this is a professional degree. As we continue to offer this module, we will be looking at ways to effectively incorporate these suggestions.

Due to the fact that this is a new educational initiative that is being created and implemented within the university, we do not have the opportunity to compare it to previous efforts. Additionally, this module focuses on teaching skills that will be applied in their other courses as well as in their future workplace. As a result, many of the benefits and lasting effects from this type of module would be seen outside of this course.

\section{DISCUSSION}

This project was an attempt to improve the teaching of important cross-disciplinary skills which have historically had trouble finding a consistent place in engineering curricula. The course module was designed to provide students with a uniform base level of information literacy and research skills that will be relevant to both coursework and professional practise. Placing this module in a course that most students will take in their first semester also ensures the maximum benefit to students throughout their coursework.

Based on our experience over two iterations of the course, this hybrid of asynchronous and synchronous teaching has definite advantages compared to the traditional classroom approaches. The online environment allowed us to use a variety of content types - text, interactive elements, graphics, videos, quizzes - to make the module more participatory and engaging for students. Splitting the module into six sections allowed students to plan their learning at a pace of their choosing. The additional amount of content compared to a 60-minute class presentation allowed us to cover more foundational concepts to ensure that all students from different universities and different backgrounds could start from a common skill set, while still including some coverage of more advanced concepts such as subject-specific databases and evaluating the credibility of documents. The live session allowed us to reinforce concepts in a more interactive way.

This approach has also had the unplanned benefit of being more accessible than a synchronous presentation for the many students in the class who are in distant time zones (as many of our students are physically located in India and have not returned to Canada even after the federal government allowed international students to reenter Canada in fall 2020). While the choice to host the module in the Brightspace LMS imposed limitations on the format of the content and the amount of interactivity we could include, ultimately, we feel it was easier for students to use the same platform that is used for their other courses. Many students have reported being overwhelmed by the number of online platforms they have to use this year; with some students reporting having used as many as twelve at uOttawa [12].

An alternative that was not considered for this project is a free-standing skills module that is not embedded in a particular course. While that option may have been more efficient by being more easily reused for other student audiences (since the contents would not be specific to a particular course), based on our previous experiences we would have had difficulty getting adequate student engagement. The assignments and feedback provided are important to the learning outcomes of this module, and even a pass/fail grade is enough to incentivize student effort. However, being hosted in a particular course space in the LMS does create obstacles for us to share the module content with other courses or groups if we desire; Brightspace does not allow modules to have open enrolment.

The module benefitted from having more collaboration with the course instructor and TAs than is normal within our work. This allowed us to tweak the content and assignments, particularly in the areas of specific skills for electrical engineering students (which was the majority of the class this year) and workplace relevance. The beta testing was also very effective at identifying technical errors and points needing clarification; however, both testers had more existing competency in research skills than the average for our target audience, which may have 
reduced their ability to provide feedback on the module's comprehensibility for beginners.

A drawback of this approach is that it can unintentionally be overly demanding of students. We had planned for the module to replace a full week of course time ( 3 hours); however, in the end, the module was made available while students were still attending other live classes for this course, meaning that during those weeks they had additional work. In addition, we had little previous course instruction experience and underestimated the length of time it would take many students to complete the module. We attempted to assess this during the beta testing of the module, however in the fall semester a number of students asked for additional time to complete it. To address this, in the most recent iteration of the module we provided the students with one month to complete the module and its assignments, prior to the live session. This is significant because university students at many levels and institutions have reported a significant increase in workload during the pandemic; at the University of Ottawa, $53 \%$ of graduate students who responded to a large survey in fall 2020 reported that workload was significantly more than expected, or more than previous semesters [12]. The time to read and view self-paced modules should be considered as lecture time in course planning, even for "soft skills" that are not part of a course's core curriculum.

This module felt at times like an awkward fit with the larger professional skills course, given that these skills are not as clearly relevant for engineering design workplaces compared to academia or to research and development jobs. While we only received one comment to date about this in the student feedback, and most students appeared to be engaged, it did create a challenge in that students had only a small opportunity to further practise these skills in the course. The final projects were fairly short and practical, with little need for information finding or research. Many students will write research papers in other courses in the weeks after the module, though we cannot review this work to assess the level of competency shown by students. For thesis students, seminars or courses in research methods are a natural fit for this content; however, for non-thesis students a self-paced module such as the one discussed here may be the best option.

\section{CONCLUSIONS}

While this project is still in the process of being implemented and is undergoing improvements after its initial launch, it has been successful so far in improving the teaching of cross-disciplinary research skills and information literacy to an audience of course-based masters' students. It was essential to address the content to both academic and workplace applications for this audience. Being embedded in a course with graded assignments is important as these skills need to be practised to be learned; however, it could create student workload challenges if it is layered on top of an existing planned course. Moving forward, we will continue to improve the module through seeking and using feedback from students, professors and colleagues. We will also look for opportunities to evaluate its success based on qualitative evaluation of submitted student work. The module content could be readily adapted for use as a learning resource for other engineering student audiences. We will aim to convert the content to an open, shareable format for use elsewhere at our institution or other universities.

\section{Acknowledgements}

The development of this online module benefited greatly from the involvement of several individuals at the University of Ottawa. We would like to thank Vice-Dean and Professor Liam Peyton who recognized the need for this type of instruction and proposed the creation and implementation of an online module, as well as Professor Sawsan Abdul-Majid for her belief in this endeavour, her feedback used to help improve the module and her time and energy in embedding it within her course. We also thank Jillian Steele for providing her advice and expertise in online pedagogy during the creation of this hybrid module, and Jennifer Gratton for graphics help. We send our thanks to Astha Tiwari and Abdullah-Al-Mehedi Hasan for providing their time, effort and thorough feedback during the testing of the module. And finally, we would like to extend our thanks to our librarian colleagues Melissa Cheung, Sarah Visintini, Mish Boutet, Nigèle Langlois and Catherine Lachaîne who provided their support and invaluable expertise reviewing the instructional methods used within the module. This work was partially supported by the University of Ottawa and Carleton University joint Shared Online Projects Initiative (SOPI) grant.

\section{References}

[1] M. Bowles-Terry and C. Donovan, "Serving Notice on the One-Shot: Changing Roles for Instruction Librarians," International Information \& Library Review, vol. 48, no. 2, pp. 137-142, Apr. 2016, doi: 10.1080/10572317.2016.1176457.

[2] S. Polkinghorne and H. Julien, "Treading Water: Results from the Longitudinal Study of Information Literacy Instruction in Canadian Academic Libraries, 1995-2017 / Comment faire du surplace: résultats de l'étude longitudinale sur la formation à la maîtrise informationnelle dans les bibliothèques universitaires canadiennes, 1995-2017," Canadian Journal of Information and Library Science, vol. 42, no. 1, pp. 6993, 2018. 
[3] S. J. Behrens, "A Conceptual Analysis and Historical Overview of Information Literacy," $C R L$, vol. 55, no. 4, pp. 309-322, Jul. 1994, doi: 10.5860/crl_55_04_309.

[4] Association of College and Research Libraries, "Framework for Information Literacy for Higher Education," Text, Feb. 2015. Accessed: Jan. 08, 2021. [Online]. Available: http://www.ala.org/acrl/sites/ala.org.acrl/files/content/iss ues/infolit/framework1.pdf.

[5] K. Mercer, K. D. Weaver, R. Figueiredo, and C. Carter, "Critical appraisal: The key to unlocking information literacy in the STEM disciplines," C\&RL News, vol. 81, no. 3, p. 145, Mar. 2020, doi: 10.5860/crln.81.3.145.

[6] J. C. Y. Zhao and M. Rabbat, "Teaching Information Literacy Skills to Senior Undergraduate Engineering Students," Proceedings of the Canadian Engineering Education Association (CEEA), Jun. 2013, doi: 10.24908/pceea.v0i0.4891.

[7] E. A. Basque, C. Brodeur, M. D. Ruisseau, J. Roberge, A. Soare, and M. Tremblay, "Credited Information Literacy Training Sessions for Graduate Students - Still Relevant after 18 years: A Case Study," presented at the 2020 ASEE Virtual Annual Conference Content Access, Jun. 2020, Accessed: Jan. 05, 2021. [Online]. Available: https://peer.asee.org/credited-information-literacytraining-sessions-for-graduate-students-still-relevantafter-18-years-a-case-study.
[8] D. Gibbs, J. Boettcher, J. Hollingsworth, and H. Slania, "Assessing the Research Needs of Graduate Students at Georgetown University," The Journal of Academic Librarianship, vol. 38, no. 5, pp. 268-276, Sep. 2012, doi: 10.1016/j.acalib.2012.07.002.

[9] University of Ottawa, "Enrolment by program," Institutional Research Planning. https://www.uottawa.ca/institutional-researchplanning/resources/facts-figures/fact-book/enrolment (accessed Mar. 03, 2021).

[10] Canadian Engineering Accreditation Board, "2019 Accreditation Criteria and Procedures." Nov. 2019, Accessed: Mar. 05, 2021. [Online]. Available: https://engineerscanada.ca/sites/default/files/accreditation /Accreditation-Criteria-Procedures-2019.pdf.

[11] A. Alwan, J. Doan, and E. P. Garcia, "Academic librarians at the forefront of IL efforts with international students in higher education," in The globalized library: American academic libraries and international students, collections, and practices, Y. Luckert and L. I. Carpenter, Eds. Chicago: Association of College and Research Libraries, A division of the American Library Association, 2018, pp. 3-18. \{ISBN 978-0-8389-8951-7\}

[12] University of Ottawa, "Distance/Online Learning Experience Student Survey," Jan. 2021.. Available: https://uottawa.saea-

tlss.ca/images/Student_Survey_Report_-_Fall_2020.pdf. 